\title{
Critical Single Proximal Left Arterial Descending Coronary Artery Stenosis to Mimic Chronic Myocardial Ischemia: A New Model Induced by Minimal Invasive Technology
}

\author{
Georg Horstick $^{\mathrm{a}, \mathrm{b}}$ Benjamin Bierbach ${ }^{\mathrm{d}}$ Nico Abegunewardene ${ }^{\mathrm{a}}$ Stefan Both $^{\mathrm{c}}$ \\ Sebastian Kuhn $^{a}$ Dirk Manefeld ${ }^{a}$ Hans-Jürgen Reinecke ${ }^{a}$ Markus Vosseler $^{a}$ \\ Andreas Helisch $^{c}$ Dietmar Becker ${ }^{a}$ Michael Lauterbach ${ }^{a} \quad$ Oliver Kempski $^{b}$ \\ Hans-Anton Lehre \\ aSecond Medical Clinic, ${ }^{b}$ Institute for Neurosurgical Pathophysiology and ${ }^{\mathrm{C} C l i n i c}$ for Nuclear Medicine, \\ Johannes Gutenberg University Mainz, and d Thoracic and Cardiovascular Surgery, University Hospitals Saarland,

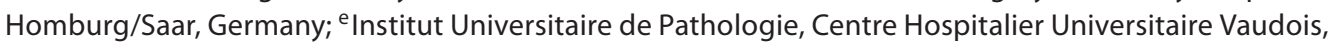 \\ Lausanne, Switzerland
}

Key Words

Stent $\cdot$ Stenosis $\cdot$ Ischemia $\cdot$ Contraction

\begin{abstract}
Background/Aims: The present report examines a new pig model for progressive induction of high-grade stenosis, for the study of chronic myocardial ischemia and the dynamics of collateral vessel growth. Methods: Thirty-nine Landrace pigs were instrumented with a novel experimental stent (GVD stent) in the left anterior descending coronary artery. Eight animals underwent transthoracic echocardiography at rest and under low-dose dobutamine. Seven animals were examined by nuclear PET and SPECT analysis. Epi-, mid- and endocardial fibrosis and the numbers of arterial vessels were examined by histology. Results: Functional analysis showed a significant decrease in global left ventricular ejection fraction $(24.5 \pm 1.6 \%) 3$ weeks after implantation. There was a trend to increased left ventricular ejection fraction after lowdose dobutamine stress $(36.0 \pm 6.6 \%)$ and a significant improvement of the impaired regional anterior wall motion.
\end{abstract}

\section{KARGER}

Fax +4161306 1234 E-Mail karger@karger.ch www.karger.com
(C) 2008 S. Karger AG, Basel

1018-1172/09/0464-0290\$26.00/0

Accessible online at:

www.karger.com/jvr
PET and SPECT imaging documented chronic hibernation. Myocardial fibrosis increased significantly in the ischemic area with a gradient from epi- to endocardial. The number of arterial vessels in the ischemic area increased and coronary angiography showed abundant collateral vessels of Rentrop class 1. Conclusion: The presented experimental model mimics the clinical situation of chronic myocardial ischemia secondary to 1-vessel coronary disease.

Copyright $\odot 2008$ S. Karger AG, Basel

For reasons of practicability and costs, experimental models of myocardial ischemia are normally performed on young, healthy and well-nutritioned animals. These models will hence solely allow to study the ischemic response of an intact myocardium, but not of a more vulnerable myocardium that has been compromised by prior low-level chronic or recurrent ischemic injuries. There is

G.H. and B.B. contributed equally to this work.
PD Dr. Georg Horstick

Johannes Gutenberg University Mainz

II Medizinische Klinik

Langenbeckstrasse 1, DE-55131 Mainz (Germany)

Tel.+496131 368073, E-Mail horstick@uni-mainz.de 
a simple reason to assume that the response of a pre-injured myocardium to an acute ischemic event will be different than that of a naive myocardium $[1,2]$. The response may either be aggravated (increased susceptibility to rhythmic problems due to chronic interstitial fibrosis) or attenuated (through improved residual blood flow via collateral arterial networks).

In the last years, intensive efforts have been undertaken to generate suitable animal models of chronic myocardial ischemia and heart failure. However, in most of these models complete coronary occlusion has eventually resulted in a well-compensated situation that has not lent itself to the study of critical coronary artery stenosis [3]. The present experiments were designed in order to overcome these limitations and to generate an animal model that could allow to study the response of chronically ischemic myocardium by using clinical methods for the assessment of ischemic or other injuries.

\section{Materials and Methods}

Percutaneous coronary intervention (PCI) with primary stent implantation was performed in a pig model with the intent to induce slowly progressing coronary artery stenosis (fig. 1). Thirtynine German Landrace pigs of either sex weighing $29.2 \pm 1.4 \mathrm{~kg}$ were prepared for PCI as recently published [4]. After quantitative vascular angiography of the proximal left arterial descending coronary artery (LAD) immediately distal to the first septal branch, a PTCA balloon was chosen with the matching diameter. Prior to stent implantation, aspirin was given as a bolus infusion at a dose of $500 \mathrm{mg}$ intravenously and $300 \mathrm{mg}$ of clopidogrel was administered via a gastric tube. The stents were composed of a copper wire with a diameter of $0.3 \mathrm{~mm}$. The wire was curved in a snakelike design and revolved around the PTCA balloon axis to form the stent tube (GVD stent) [5]. The $10-\mathrm{mm}$ stent was mounted on the 20-mm PTCA balloon and delivered by standard angioplasty guide catheters and wires (fig. 1). For stent implantation, the PTCA balloon was expanded to a nominal balloon pressure in order to avoid acute arterial injury by overexpansion (fig. 2b). After the intervention, an angiography of the intervened vessel was performed to document patency (fig. 2c).

Coronary angiography was repeated each week in order to document the development of coronary flow obstruction according to established Thrombolysis in Myocardial Infarction (TIMI) criteria [6]. The evaluation was performed by 2 separate investigators (N.A. and M.V.) who were blinded to animal identification number and time point after stent implantation. For a more objective evaluation of the reduced angiographic inflow of contrast medium across the implanted stent, the angiographic criteria of a modified TIMI frame count were applied [7, 8]. To evaluate coronary flow, we counted the number of heart beats that were required for the contrast medium to reach standard distal coronary landmarks of the LAD in the anterior-posterior or lateral plane. Reduced coronary blood flow reaching the distal landmarks (apex) at 3 or more

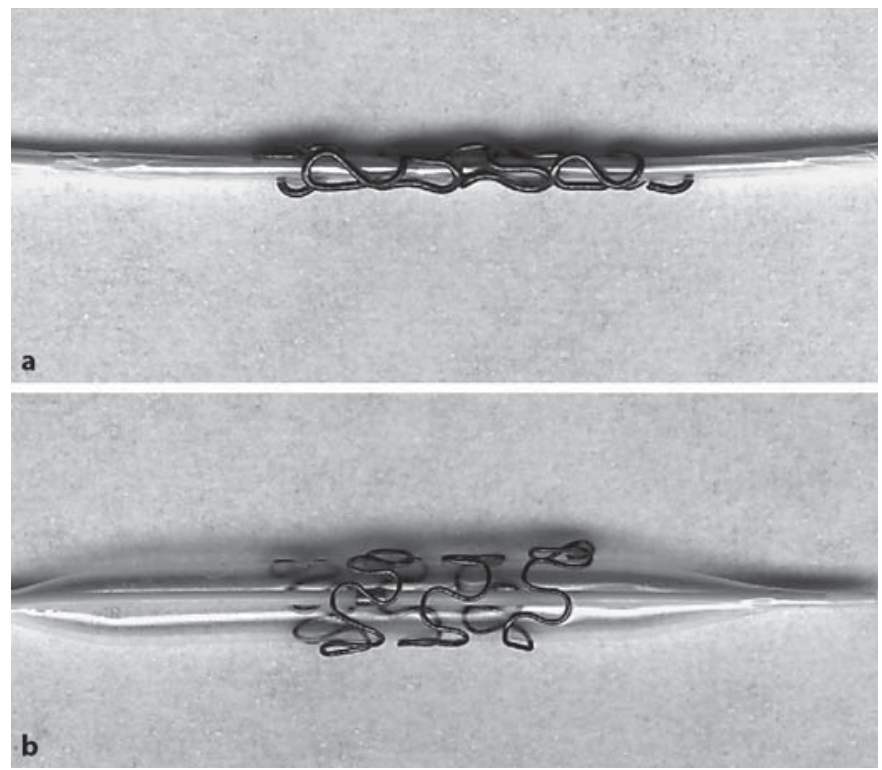

Fig. 1. Mounted GVD-stent on a PTCA balloon before (a) and after expansion (b).

heart cycles was considered TIMI II 'slow' flow in contrast to TIMI II 'fast' flow which required only $1-2$ beats $[9,10]$. Pilot experiments evaluating the TIMI frame count showed a good correlation for the differentiation of TIMI II fast and slow flow gradation. In contrast to the measurement of the TIMI frame count, the determination of TIMI II slow and fast flow at coronary examination served as a good measure for the evaluation of the hemodynamic status of the coronary stent stenosis in relation to the regional myocardial function. Coronary collateralization was determined by angiography according to the Rentrop classification [11].

Histological and Immunohistochemical Staining Methods

Histological analyses were performed when coronary flow presented TIMI II slow flow at angiography. After cardioplegic arrest, the heart was perfusion fixed $(70 \mathrm{~mm} \mathrm{Hg})$ with $4 \%$ buffered paraformaldehyde and dissected perpendicular to the left ventricular long axis from the apex to the base in $10-\mathrm{mm}$-thick slices. Wholemount histological sections with a thickness of $4 \mu \mathrm{m}$ were created from the short-axis specimens. Histological examinations of the fibrosis and arterial density were performed by Sirius red staining and polarization microscopy on digitized images in a blinded fashion (fig. 3) $[4,12,13]$. The left ventricle was divided into $8 \mathrm{sec}-$ tors starting at the LAD and counting in a clockwise manner (fig. 4a). Arterial vessels with a diameter exceeding $15 \mu \mathrm{m}$ were manually counted in each of the 8 sectors in the epi-, mid- and endocardial third inside a rectangle of $450 \times 450 \mu \mathrm{m}$.

All investigative procedures and animal facilities conformed with the Guide for the Care and Use of Laboratory Animals published by the National Institutes of Health. The protocol was approved by the Institutional Animal Care and Use Committee.

\section{Transthoracic Echocardiography}

Semiquantitative transthoracic echocardiography (TTE) examination was performed at each coronary angiography to deter- 

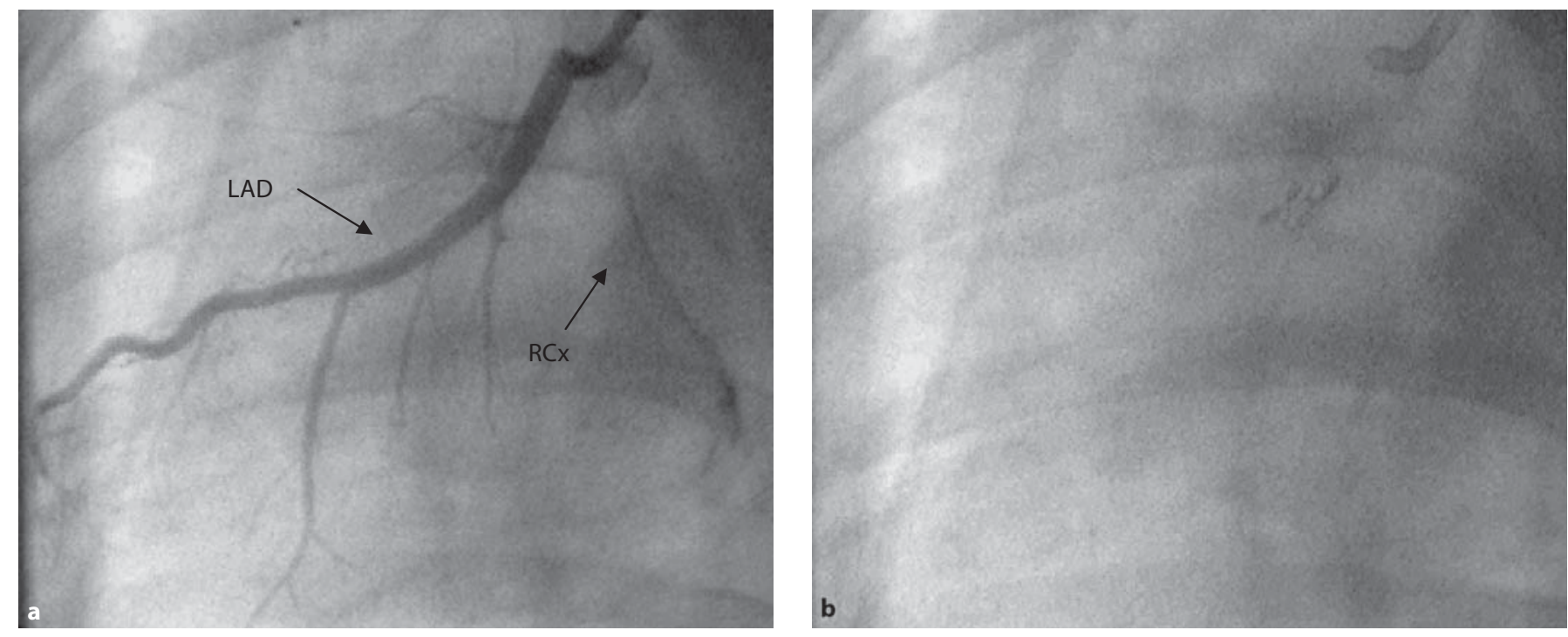

Fig. 2. a Angiography of the left coronary artery with the LAD and the circumflex artery (RCx) before stent implantation. b Implanted stent. c Angiography after stent implantation.

mine anterior wall motion in the two-dimensional long axis 2chamber view. In 8 animals, a quantitative analysis including a dobutamine stress test at the time of angiographic TIMI II slow flow was performed using Sonos 500 (Hewlett Packard; fig. 5) equipped with a 2.5 - and $3.5-\mathrm{MHz}$ transthoracic echo probe. An electrocardiogram was recorded simultaneously, and end diastole and end systole were defined according to a previous publication [14]. The quantitative analysis was performed from digitized frames with a semiautomatic computer system (Echocom 2.0; Individual Software $\mathrm{GmbH}$ ). Extrasystolic and postextrasystolic cycles were excluded from the analysis.

Wall thickening was measured along 50 chords automatically drawn perpendicular to the left ventricular centerline. Chords started at the transition of the mitral valve ring with the anterior wall (first chord) and ended at the transition of the posterior part of the mitral valve ring and the posterior myocardial wall (last chord). Hence, chords 10-25 mainly represent the anterolateral

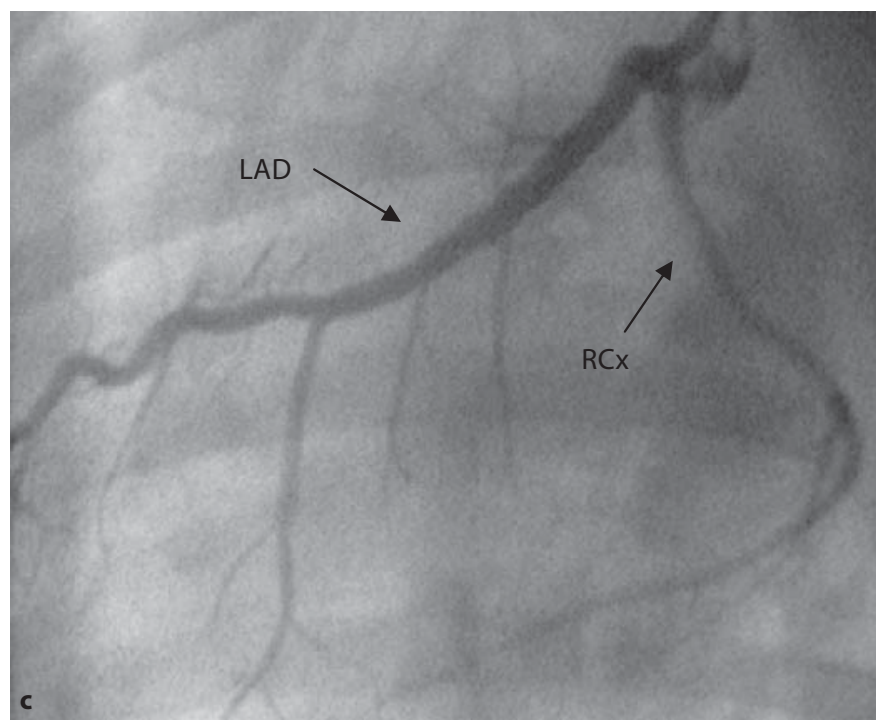

wall. In order to detect relevant differences in wall motion, each individual chord of the regional wall motion analysis under ischemia at rest was compared with dobutamin stress testing and with pre-implantation baseline control values.

\section{Single Photon Emission Computed Tomography and}

${ }^{18}$ F-Deoxyglucose Positron Emission Tomography Analysis

In 7 of the 8 animals, combined ${ }^{18} \mathrm{~F}$-deoxyglucose (FDG) positron emission tomography (PET) and ${ }^{99 \mathrm{~m} T c-M I B I-s i n g l e ~ p h o t o n ~}$ emission computed tomography (SPECT) examinations were performed and the results were presented in a 37-segment bull's eye view (fig. 4a). Segments were defined as infarcted if the average reduction of blood flow and metabolism exceeded 50\% compared to the segment with the maximum uptake. Hibernating myocardium was defined as a relative FDG uptake of more than $60 \%$ but with a flow of less than $50 \%$ of the maximum uptake according to previously published criteria [15]. 

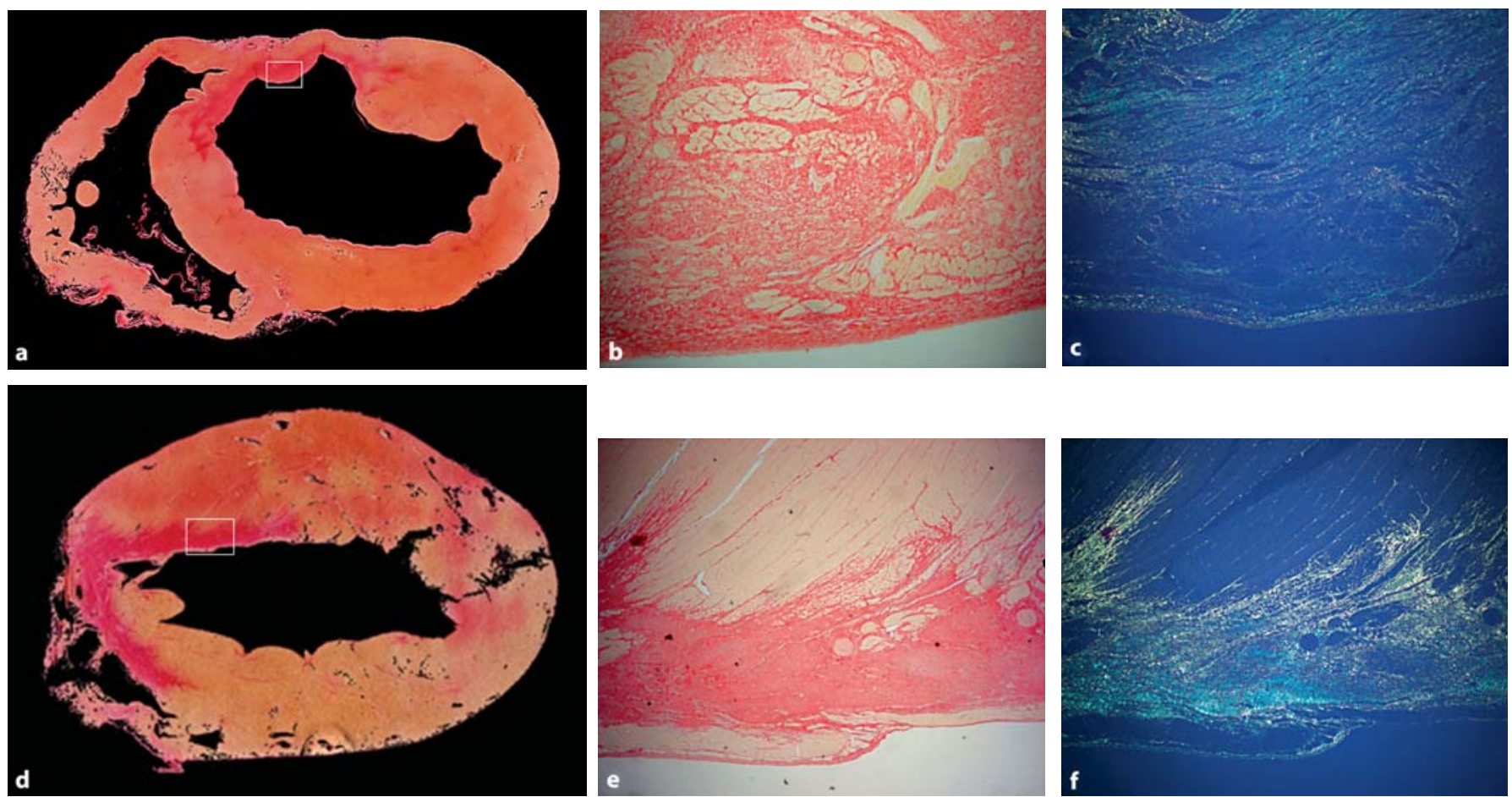

Fig. 3. a Large cross-sectional slice with Sirius red staining in an animal with chronic myocardial ischemia. b Magnification presenting the diffuse endocardial fibrosis. $\times 200$. c Polarization microscopy presenting the lightening of the collagen fibers. $\times 200$. d Example of a large cross-section slice in an animal 3 weeks after acute myocardial infarction. e Magnification showed the large fibrotic tissue in contrast to chronic myocardial ischemia. $\times 200$. $f$ Polarization microscopy documented the increased amount of collagen in contrast to chronic ischemia. $\times 200$.
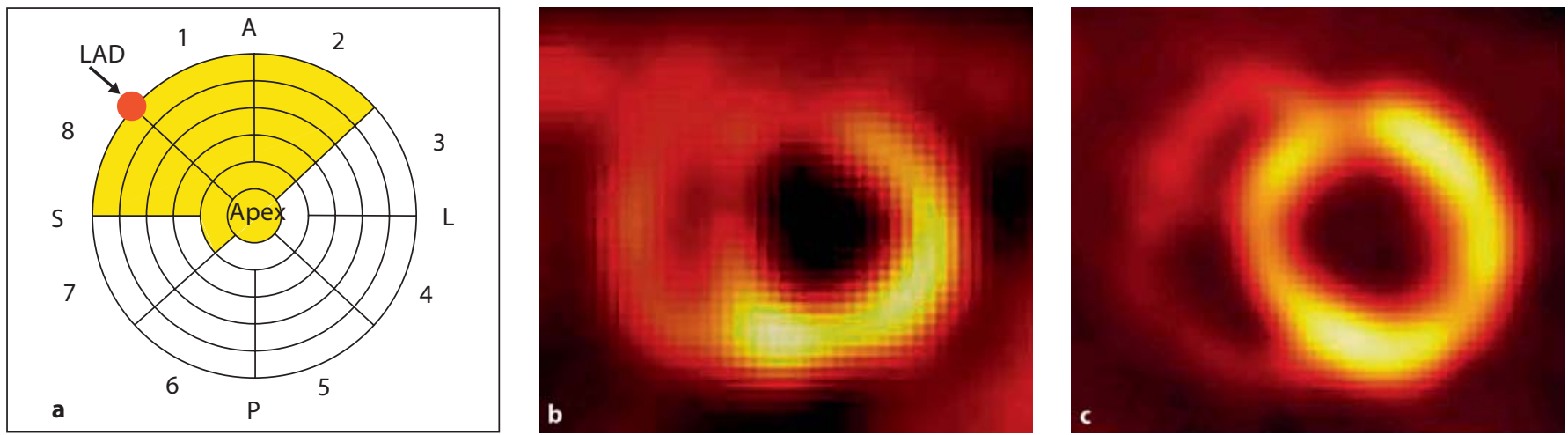

Fig. 4. a Thirty-seven sectors bull's eye plot from the apex in the center to the basal slices at the outside of the plot. Anterior wall (A) is shown at the top of the plot. Sectors are counted clockwise starting with sector 1 at the LAD. b Example of the SPECT imaging showing the perfusion defect in the anterior-septal and anterior area. c Example of PET imaging presenting viable myocardium with some signal reduction in the anterior wall. 


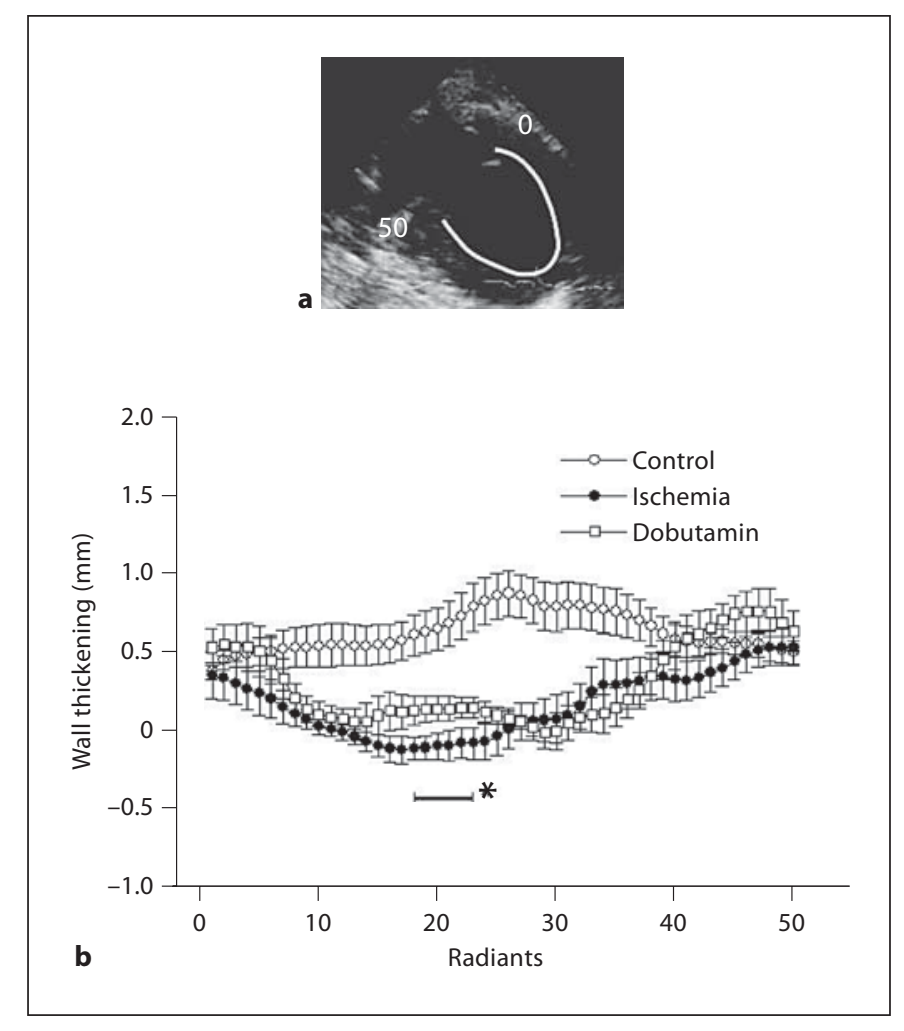

Fig. 5. a Longitudinal 2-chamber TTE with the overlay of the 50 radiants. Base of the heart is at the mitral valve level at radiants 0 and 50, apex at radiant 25. b Quantitative regional wall motion analysis using the fixed centerline method. Wall thickening was measured along 50 chords automatically drawn perpendicular to the centerline in 8 animals. Wall thickening of radiants 18-23 presented a significant increase under low-dose dobutamine stress echocardiography. ${ }^{*} \mathrm{p}=0.0014$.

For SPECT analysis, on average $145 \mathrm{MBq}{ }^{99 \mathrm{~m}} \mathrm{Tc}-\mathrm{MIBI}$ was injected intravenously $1 \mathrm{~h}$ prior to examinations. For measurement of ${ }^{99 m}$ Tc-MIBI, an IRIX gamma camera was used with the 102 Cardiac program (Siemens). The data were recorded with a 64 matrix and a zoom of 1.6 in the continuous mode. The total time for data acquisition was $23 \mathrm{~min}$ on average with $40 \mathrm{~s}$ per step. Twodimensional reconstruction in the short, longitudinal (2-chamber view) and horizontal axis (4-chamber view) was performed. PET scans were performed on the following day after SPECT analysis using FDG as a tracer for examination of the myocardial metabolism under euglycemic clamping by insulin and glucose infusion and monitoring of blood glucose levels $[16,17]$. The insulin infusion was calculated with insulin $=0.25 \times \mathrm{kg}$ body weight/h, dissolved in $50 \mathrm{ml}$ physiological saline and infused by $48 \mathrm{ml} / \mathrm{h}$. The parallel glucose (20\%) infusion was calculated by the formula: glucose $20 \%(\mathrm{ml} / \mathrm{h})=0.3 \times \mathrm{kg}$ body weight. The average activity injected intravenously was $245 \mathrm{MBq}$ FDG. Under continuous blood glucose infusion and monitoring, dynamic data acquisition was performed.

\section{Statistical Analysis}

Data are presented as mean values \pm SEM. Statistical analysis was performed with Sigma Stat ${ }^{\circledR} 3.0$ (Jandel Corp.). The statistical significance of differences before and after PCI were determined with paired Student's t test, between the control vessels and the dilated vessels with the $t$ test and between groups with one-way analysis of variance. If data did not present normal distribution, the Kruskal-Wallis one-way analysis of variance on rank test was used. A two-sided $\mathrm{p}<0.05$ was considered statistically significant.

\section{Results}

A high-grade coronary artery stenosis of more than $90 \%$ of the vessel lumen was obtained in 21 of 39 pigs. Among the other 18 animals, 10 died of sudden death and 4 of postoperative bleeding from the puncture site. One animal developed severe pericarditis at follow-up and 1 animal showed massive pulmonary embolism. Finally, 2 animals survived, but failed to develop significant coronary stent stenosis. None of the pigs which died due to sudden death revealed any fresh coronary thrombosis at autopsy. Arrhythmic events were suspected but could not be proven.

\section{Coronary Angiography}

Under continuous angiographic control, 21 of 39 animals developed TIMI II fast flow after a mean follow-up of $13.3 \pm 1.0$ days and TIMI II slow flow was documented at $20 \pm 1.5$ days after stent implantation. Angiographic coronary stenosis was $90-95 \%$ in all animals with TIMI II slow flow. Neither complete occlusion (TIMI 0 flow) nor subtotal occlusion (TIMI 1 flow) were encountered.

In respect to the growth of collateral arteries, 17 of the 21 animals developed Rentrop grade 1 angiographic collateral blood flow. Three animals presented no noteworthy collateral blood flow at the end of the observation period. Only 1 animal presented angiographic Rentrop grade 2 collateral flow (example in fig. 6, 7).

\section{Echocardiography}

TIMI grade II fast flow was not associated with a reduction in regional wall motion. Hypokinesia at rest was observed only when TIMI grade II slow flow had been documented by angiography. Ejection fractions were significantly reduced $(24.5 \pm 1.6 \%$, versus $67.6 \pm 4.3 \%$ before PCI, p < 0.001). Upon infusion of $10 \mu \mathrm{g} / \mathrm{kg} / \mathrm{min}$ dobutamine intravenously, the global ejection fraction showed partial, albeit statistically nonsignificant recovery to $36 \pm 6.6 \%(n=8, p=0.09)$. Reduced anterior wall 

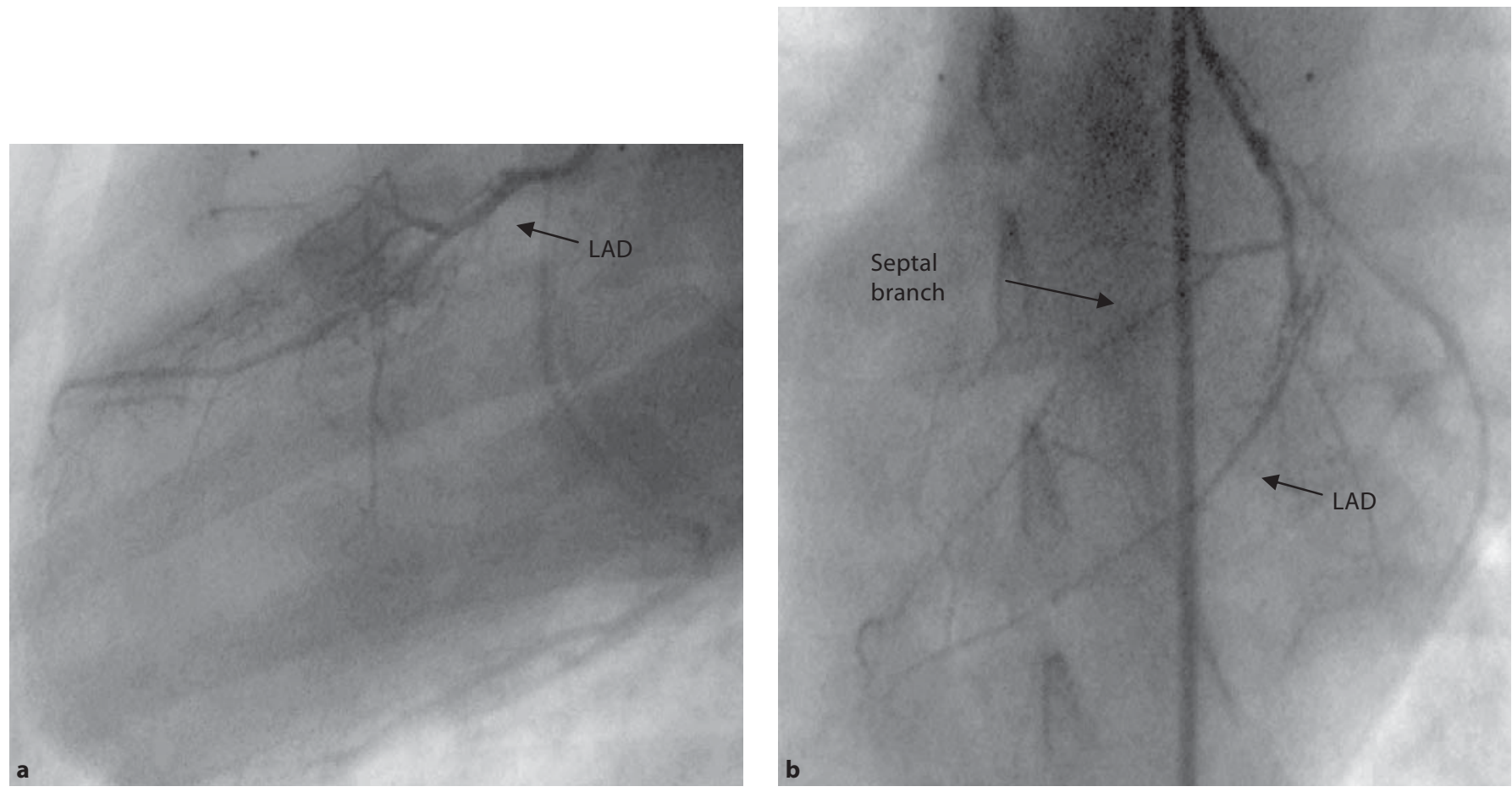

Fig. 6. Angiographic control of the same animal of figure 2 three weeks after stent implantation. High-grade coronary artery stenosis of the LAD in the stent area with collaterals Rentrop class 2 via the septal branches. a Lateral view. b Anterior-posterior view.
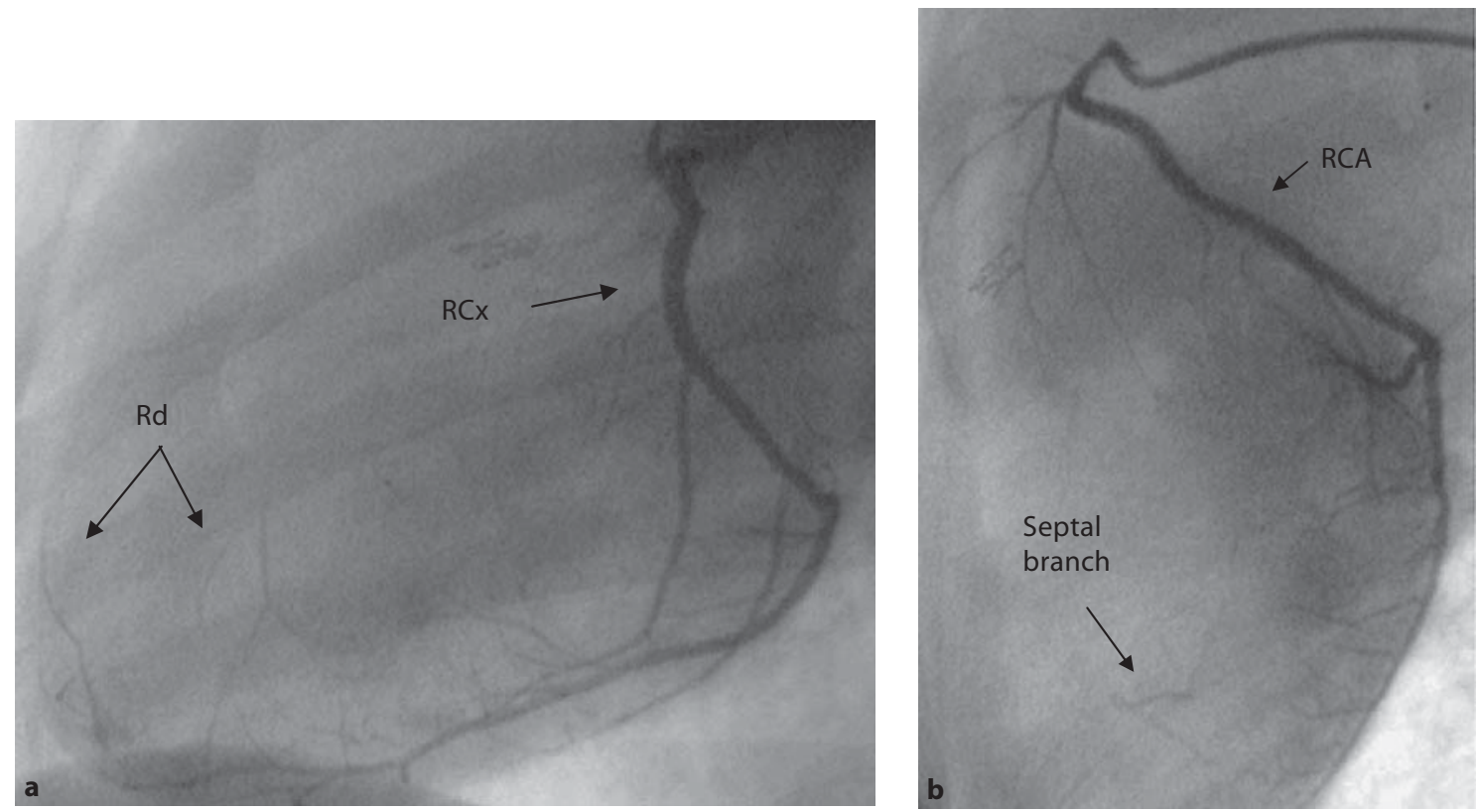

Fig. 7. Angiographic control of the same animal as in figure 2 three weeks after stent implantation. a Selective contrast injection of the circumflex artery $(\mathrm{RCx})$ with collaterals of Rentrop class 2 via the diagonal branches (Rd). b Contrast injection of the right coronary artery (RCA) with collaterals via the septal branches. 


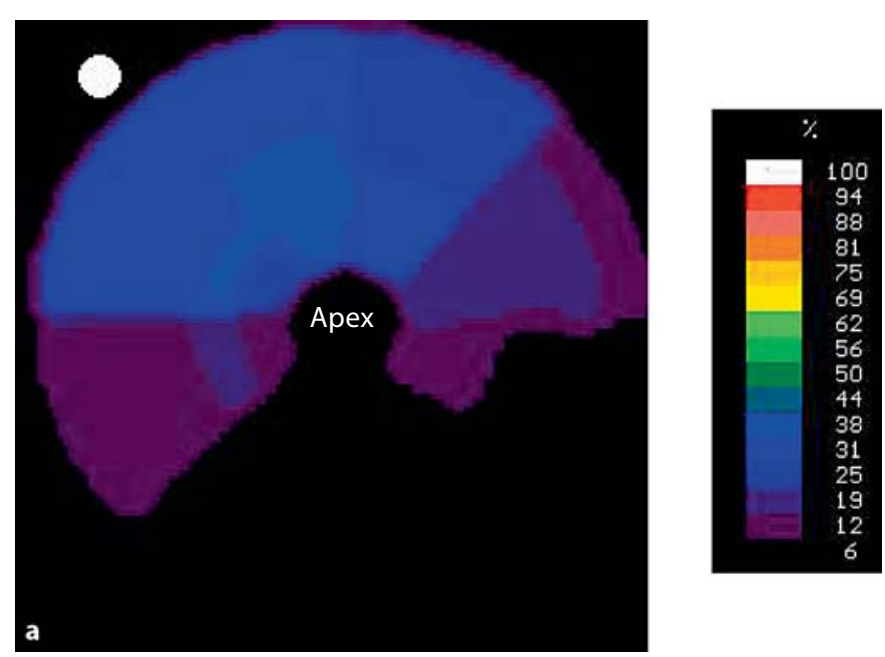

Fig. 8. Bull's eye plots according to figure 4a presenting myocardial fibrosis. a Percentage of transmural myocardial fibrosis in each sector. Epicardial (b), midmyocardial (c) and endocardial (d) fibrosis in each sector.
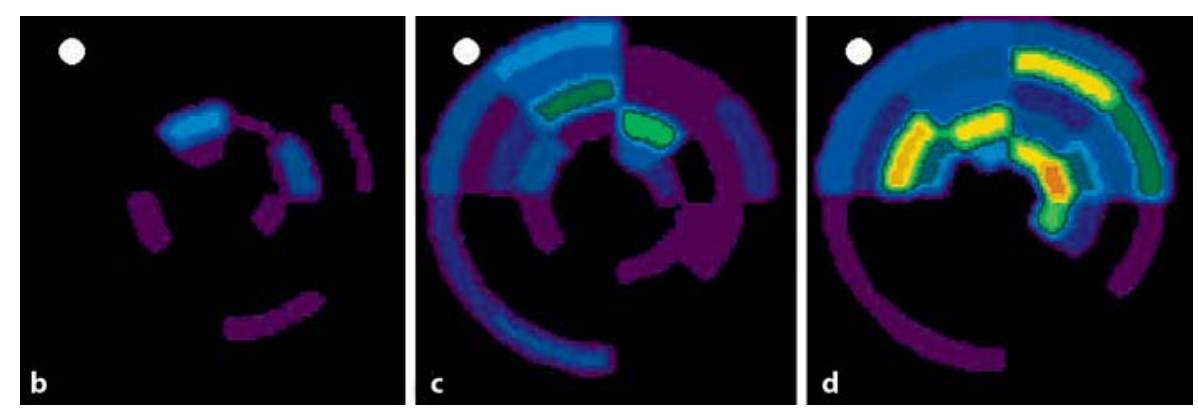

thickening between chords 18 and 23 was significantly improved under low-dose dobutamine infusion (-0.09 \pm 0.05 vs. $0.14 \pm 0.03 \mathrm{~cm}, \mathrm{p}=0.0014$; fig. $5 \mathrm{~b}$ ).

\section{Histological Examinations}

The mean percentage of fibrosis in the left ventricle was $19.2 \pm 13.7 \%$ (fig. 8 ). The amount of fibrosis was significantly more pronounced in the ischemic areas (34.7 $\pm 13.7 \%$, sectors 1,2 and 8 ) than in the nonischemic control sector $5(5.4 \pm 3.3 \% ; \mathrm{p}=0.0078)$. The differentiation between the epi-, mid- and endocardial third concerning the percentage of fibrosis in all sectors of the left ventricular presented an increase from outside to inside which was significant for the epicardial versus the mid- and endocardial areas (epicardial $13.4 \pm 1.6 \%$, midcardial 20.2 $\pm 2.3 \%$, endocardial $23.9 \pm 2.7 \%$; $p=0.017$; fig. $8 b-d$ ).

The number of arterioles exceeding $15 \mu \mathrm{m}$ in diameter per myocardial tissue surface was significantly higher in the ischemic sectors $\left(1,2\right.$ and 8: $\left.66.0 \pm 7.5 / \mathrm{mm}^{2}\right)$ versus the nonischemic control sector $5\left(28.5 \pm 5.5 / \mathrm{mm}^{2}\right.$, $\mathrm{p}=0.0078)$. There was a trend towards an increase in vessel density in the ischemic sectors from epi- to endocardium, however, being not statistically significant (epi- cardial $53.5 \pm 7 / \mathrm{mm}^{2}$, midcardial $65.5 \pm 9 / \mathrm{mm}^{2}$, endocardial $78.5 \pm 11 / \mathrm{mm}^{2} ; \mathrm{p}=0.078$ ). As expected, the number of vessels in the nonischemic region did not show significant differences between endo-, mid- and epicardial areas (endocardial $26.5 \pm 8 / \mathrm{mm}^{2}$, midcardial $36 \pm$ $6 / \mathrm{mm}^{2}$, epicardial $23 \pm 3.5 / \mathrm{mm}^{2} ; \mathrm{p}=0.48$ )

\section{PET and SPECT Examinations}

According to the current definitions (see above), 27\% of all left ventricular myocardial bull's eye segments presented criteria of hibernation. Of all sectors, $2.7 \%$ were nonviable with concordant blood flow/metabolism reduction in the SPECT and PET analysis.

\section{Discussion}

The results of our chronically instrumented pig model demonstrated that the implanted stent induced a gradually evolving severe coronary artery stenosis. Combined FDG-PET/MIBI-SPECT imaging and low-dose dobutamine stress TTE presented the functional status of chronic hibernation in the anterior wall. 
Several different techniques for induction of coronary artery stenosis have been published previously [3]. In most of these models, external constrictors were implanted by operative thoracotomy and surgical vessel dissection [18-22]. Most commonly, the Ameroid constrictor has been placed around the circumflex artery, and this has repeatedly led to complete coronary artery occlusion $[18,23,24]$. Nevertheless, impaired regional wall thickening recovered after 3 weeks with return to normal at 5 weeks [20]. The mortality rate was about 30\% [3].

Different results were published using a surgically implanted constrictor with an initially fixed stenosis. Depending on the inner lumen diameter, the results regarding the adaption of global left ventricular ejection fraction (LV-EF) to blood flow reduction ranged from mild to moderate [21,25]. High-grade coronary artery stenosis was seen in about one third of the animals and total occlusion in the majority of the animals after 3 months. Hibernating myocardium with diffuse myocardial fibrosis was observed after 1 month with approximately 6$6.5 \%$ fibrosis in the ischemic area, which is less than reported clinically [26]. Reduction in LV-EF was moderate (49\%) [21]. In contrast, our present study showed a severe decrease in left ventricular function and a higher amount of fibrosis in the ischemic area, more compatible with the clinical situation.

If mandatory, experimental quantitative blood flow control can be achieved by implantation of a cuff or hydraulic occluder, especially in combination with a Doppler flow probe $[19,22]$. However, that procedure requires extensive surgical instrumentation and the lack of durability of the cuff poses a major technically challenge. In our present study, setting coronary flow was differentiated in angiographically TIMI II slow and fast flow, thus allowing the evaluation of the hemodynamic status of the stenosis in relation to regional myocardial function [9]. Clearly, SPECT analysis documented myocardial hypoperfusion, but noninvasive blood flow quantification might be more reliably accomplished by using MRI in future experiments [27].

Four different types of stent models have so far been reported [28-31]. Similar to previous studies, the induction of stent stenosis in the present study was caused by a local inflammatory reaction. However, in our study, complete occlusion was not seen, but rather hibernating as defined by the criteria of Matsunari et al. [15]. The histological findings of an increase in capillary density and diffuse myocardial fibrosis without relevant infarction are in accord with human studies on hibernating myocardium $[26,32]$.
In conclusion, the present results documented the suitability of this experimental model to mimic the clinical situation of chronic myocardial ischemia, with adaptation of myocardial function based on a 1-vessel coronary artery disease.

\section{Limitations}

Due to limited capacities of our nuclear medicine facilities, only 7 animals could be subjected to combined SPECT and FDG-PET analysis. It may be criticized that exact quantification of the collateral blood was not performed. Yet, by angiographic examination, we found grade 1 collaterals according to the Rentrop classification. The mortality rate in this model is certainly iatrogenic, in the first place due to the severe reduction in LVEF secondary to the proximal position of the stent. The study includes the first experiments using this type of stent and it may be expected that mortality will be decreased with technical improvement of the procedure. Mortality in respect to the reduced LV-EF in this model is similar to the clinical situation. Finally, it should be stressed that any animal model of human chronic disease will suffer from the fact that disease induction will be much faster than in the clinical situation of our patients.

\section{Acknowledgments}

The authors thank Angelica Karpi, Nicole Papaniaou, Claudia Braun and Antonietta Valentino for their excellent technical assistance. We also thank Mr. F. Jungbluth (Waidhaus, Germany) for his cooperation.

References
Heusch G: Hibernating myocardium. Physiol Rev 1998;78:1055-1085.

2 Schwartz PJ, Billman GE, Stone HL: Autonomic mechanisms in ventricular fibrillation induced by myocardial ischemia during exercise in dogs with healed myocardial infarction: an experimental preparation for sudden cardiac death. Circulation 1984;69: 790-800.

- 3 Hughes GC, Post MJ, Simons M, Annex BH: Translational physiology: porcine models of human coronary artery disease: implications for preclinical trials of therapeutic angiogenesis. J Appl Physiol 2003;94:16891701. 
4 Horstick G, Bierbach B, Schlindwein P, Abegunewardene $\mathrm{N}$, Vosseler $\mathrm{M}$, Bittinger $\mathrm{F}$, Becker D, Lauterbach M, Lehr H-A, Kempski $\mathrm{O}$ : Resistance of the internal mammary artery to restenosis: a histomorphologic study of various porcine arteries. J Vasc Res 2008; 45:45-53.

5 Horstick G: Implantat und Verfahren zur Simulation einer schweren Minderdurchblutung verschiedener Organe im Tiermodell auf minimal invasivem Wege ohne Gefahr eines akuten Zelltodes. Offenlegungsschrift des Patentes. DE 10130461 A1, 2003.

6 Sheehan FH, Braunwald E, Canner P, Dodge HT, Gore J, Van Natta P, Passamani ER, Williams DO, Zaret B: The effect of intravenous thrombolytic therapy on left ventricular function: a report on tissue-type plasminogen activator and streptokinase from the Thrombolysis in Myocardial Infarction (TIMI Phase I) trial. Circulation 1987;75: 817-829.

7 Gibson CM, Cannon CP, Piana RN, Maher KM, Davis SF, Diver DJ, Kuntz RE, Baim DS, Braunwald E: Relationship of coronary flow to myocardial infarction size: use of new simple methods to subclassify TIMI 2 and 3 flows. Circulation 1992;86(suppl I):I-453.

$\checkmark 8$ Gibson CM, Cannon CP, Daley WL, Dodge JT Jr, Alexander B Jr, Marble SJ, McCabe CH, Raymond L, Fortin T, Poole WK, Braunwald E: TIMI frame count: a quantitative method of assessing coronary artery flow. Circulation 1996;93:879-888.

-9 Piana RN, Paik GY, Moscucci M, Cohen DJ, Gibson CM, Kugelmass AD, Carrozza JP Jr, Kuntz RE, Baim DS: Incidence and treatment of 'no-reflow' after percutaneous coronary intervention. Circulation 1994;89: 2514-2518

10 Popma JJ, Bashore TM: Qualitative and quantitative angiography; in Topol EJ (ed): Textbook of Interventional Cardiology, ed 2. Philadelphia, WB Saunders, 1994, pp 10521068.

11 Rentrop K, Cohen M, Blanke H, Phillips R: Changes in collateral channel filling immediately after controlled coronary artery occlusion by an angioplasty balloon in human subjects. J Am Coll Cardiol 1985;5:587-592.

-12 Junqueira LC, Bignolas G, Brentani RR: Picrosirius staining plus polarization microscopy, a specific method for collagen detection in tissue sections. Histochem J 1979;11: 447-455.
13 Junquiera LC, Junqueira LC, Brentani RR: A simple and sensitive method for the quantitative estimation of collagen. Anal Biochem 1979;94:96-99.

14 Horstick G, Heimann A, Gotze O, Hafner G, Berg O, Boehmer P, Becker P, Darius H, Rupprecht H, Loos M, Bhakdi S, Meyer J, Kempski O: Intracoronary application of C1 esterase inhibitor improves cardiac function and reduces myocardial necrosis in an experimental model of ischemia and reperfusion. Circulation 1997;95:701-708.

15 Matsunari I, Boning G, Ziegler SI, Nekolla SG, Stollfuss JC, Kosa I, Ficaro EP, Schwaiger M: Attenuation-corrected ${ }^{99 m}$ Tc-tetrofosmin single-photon emission computed tomography in the detection of viable myocardium: comparison with positron emission tomography using ${ }^{18} \mathrm{~F}$-fluorodeoxyglucose. J Am Coll Cardiol 1998;32:927-935.

16 Martin WH, Jones RC, Delbeke D, Sandler MP: A simplified intravenous glucose loading protocol for fluorine-18 fluorodeoxyglucose cardiac single-photon emission tomography. Eur J Nucl Med 1997;24:1291-1297.

17 Ng CK, Soufer R, McNulty PH: Effect of hyperinsulinemia on myocardial fluorine-18 FDG uptake. J Nucl Med 1998;39:379-383.

18 Litvak J, Siderides LE, Vineberg AM: The experimental production of coronary artery insufficiency and occlusion. Am Heart 1957;53:505-518.

19 Bolukoglu H, Liedtke AJ, Nellis SH, Eggleston AM, Subramanian R, Renstrom B: An animal model of chronic coronary stenosis resulting in hibernating myocardium. Am J Physiol 1992;263:H20-H29.

20 Shen YT, Vatner SF: Mechanism of impaired myocardial function during progressive coronary stenosis in conscious pigs: hibernation versus stunning? Circ Res 1995;76:479-488.

21 Fallavollita JA, Perry BJ, Canty JM Jr: 18F-2deoxyglucose deposition and regional flow in pigs with chronically dysfunctional myocardium: evidence for transmural variations in chronic hibernating myocardium. Circulation 1997;95:1900-1909.

22 St Louis JD, Hughes GC, Kypson AP, DeGrado TR, Donovan CL, Coleman RE, Yin B, Steenbergen C, Landolfo KP, Lowe JE: An experimental model of chronic myocardial hibernation. Ann Thorac Surg 2000;69:13511357.
23 O’Konski MS, White FC, Longhurst J, Roth D, Bloor CM: Ameroid constriction of the proximal left circumflex coronary artery in swine: a model of limited coronary collateral circulation. Am J Cardiovasc Pathol 1987;1: 69-77.

24 Carroll SM: Enhancement of coronary collateral development by therapeutic angiogenesis. Cardiovasc Pathobiol 1997;2:12-24.

25 Millard RW: Induction of functional coronary collaterals in the swine heart. Basic Res Cardiol 1981;76:468-473.

26 Elsasser A, Decker E, Kostin S, Hein S, Skwara W, Muller KD, Greiber S, Schaper W, Klovekorn WP, Schaper J: A self-perpetuating vicious cycle of tissue damage in human hibernating myocardium. Mol Cell Biochem 2000;213:17-28.

-27 Schmitt M, Horstick G, Petersen SE, Karg A, Hoffmann N, Gumbrich T, Abegunewardene N, Schreiber WG: Quantification of resting myocardial blood flow in a pig model of acute ischemia based on first-pass MRI. Magn Reson Med 2005;53:1223-1227.

$>28$ Staab ME, Srivatsa SS, Lerman A, Sangiorgi G, Jeong MH, Edwards WD, Holmes DR Jr, Schwartz RS: Arterial remodeling after experimental percutaneous injury is highly dependent on adventitial injury and histopathology. Int J Cardiol 1997;58:31-40.

29 von Degenfeld G, Raake P, Kupatt C, Lebherz C, Hinkel R, Gildehaus FJ, Munzing W, Kranz A, Waltenberger J, Simoes M, Schwaiger M, Thein E, Boekstegers P: Selective pressure-regulated retroinfusion of fibroblast growth factor- 2 into the coronary vein enhances regional myocardial blood flow and function in pigs with chronic myocardial ischemia. J Am Coll Cardiol 2003;42: 1120-1128.

30 Dymarkowski S, Szilard M, Maes A, Liu XS, Huang YM, Verbeken E, Mortelmans L, Bogaert J, De Scheerder I: Assessment of myocardial viability in a porcine model of chronic coronary artery stenosis with dual dose dobutamine magnetic resonance imaging. Int J Cardiovasc Imaging 2003;19:63-72.

>31 Song W, Lee J, Kim H, Shin J, Oh D, Tio F, Wong SC, Hong MK: A new percutaneous porcine coronary model of chronic total occlusion. J Invasive Cardiol 2005; 17:452454.

32 Elsasser A, Schlepper M, Klovekorn WP, Cai WJ, Zimmermann R, Muller KD, Strasser R, Kostin S, Gagel C, Munkel B, Schaper W, Schaper J: Hibernating myocardium: an incomplete adaptation to ischemia. Circulation 1997;96:2920-2931. 